\title{
The technological knowledge used by technology education students in capability tasks
}

\author{
Willem Rauscher \\ University of Pretoria, South Africa \\ willem.rauscher@up.ac.za
}

\begin{abstract}
Since technology education is, compared to subjects such as mathematics and science, still a fairly new subject both nationally and internationally, it does not have an established subject philosophy. In the absence of an established subject philosophy for technology education, one can draw on other disciplines in the field, such as engineering and design practice, for insights into technological knowledge. The purpose of this study is to investigate the usefulness of an epistemological conceptual framework chiefly derived from engineering, to be able to describe the nature of technological knowledge, in an attempt to contribute towards the understanding of this relatively new learning area. The conceptual framework was derived mainly from Vincenti's (1990) categories of knowledge based on his research into historical aeronautic engineering cases. Quantitative research was used to provide insight into the categories of knowledge used by students at the University of Pretoria during capability tasks and included an analysis of a questionnaire administered to these students. Findings suggest that the conceptual framework used here is useful in technology education and that the categories of technological knowledge apply to all the content areas, i.e. structures, systems and control, and processing, in technology education. The study recommends that researchers and educators deepen their understanding of the nature of technological knowledge by considering the categories of technological knowledge presented in the conceptual framework.
\end{abstract}

Keywords: technological knowledge, categories of technological knowledge, technology education, epistemology

\section{INTRODUCTION}

The advent of technology ${ }^{1}$ education, nationally and internationally, has posed challenges different from those experienced in regard to the other learning areas. In contrast to the other learning areas which have, at least for particular components, a well-founded subject philosophy, there is as yet no established subject philosophy for technology education (Ankiewicz, De Swart, \& De Vries, 2006:117-118). Technology education is in fact still a fairly new subject globally without a large research base and a well-established culture of classroom practice (Mawson, 2007:253). The importance of a philosophy of technology is acknowledged by De Vries (2005:8) who notes that it can, inter alia, provide a conceptual basis and proper understanding of technology and help identify a research agenda for educational research in technology education.

\footnotetext{
${ }^{1}$ For the purpose of this study the term technology will be used in the broader sense where the term technology includes everything the engineer calls technology, along with engineering itself (Mitcham, (1994:143-144). In line with De Vries's (2005:11-12) approach, the term (technology or engineering) used in this paper will be led by the literature referred to in that particular case. Also, the terms technology education and technology are used interchangeably.
} 
One way through which technology can be conceptualized and better understood is "technology as knowledge" (epistemology as a field in philosophy) (Mitcham, 1994:154160). Herschbach (1995:32) notes that the recognition of the centrality of knowledge leads to conceiving technology as more than artefact, technique and process. In addition, it makes little sense to talk about curricular strategies until the epistemological dimensions of technological knowledge have been determined (Herschbach, 1995:32). Rowell, Gustafson, and Guilbert (1999:39) argue that the pedagogical implications for technology education arise from the epistemological debate about the nature of technological knowledge. Also, since it is impossible to undertake a technological activity without technological knowledge and the utilisation and transformation of other knowledge bases (Jones, 2003:89), an inquiry into 'technology as knowledge' seems appropriate.

Pavlova (2005:127) notes that the importance of knowledge and the understanding of technology are identified as an area of concern by a number of authors. Yet, the epistemology of technology is by no means a fully developed area (De Vries \& Tamir, 1997:7; Gibson, 2008:3). In the absence of an established subject philosophy for technology education, one can draw on the philosophy and history of engineering, as well as design methodology for insights into technological knowledge (Broens \& De Vries, 2003:459-460).

Although engineering, philosophy of technology and design methodology provide frameworks through which technology can be conceptualized, in order to be useful in an educational context, they need to be validated by educators, and data needs to be gathered from students in order to begin to develop an idea of the form of technological knowledge (Compton, 2004:17). Compton (2004:14) emphasises that "It is essential that we acknowledge that technology education cannot expect to 'operationalise' frameworks from technology into technology education without clearly exploring the fitness of doing so ...".

The purpose and significant contribution of this study therefore, is to investigate the usefulness of an epistemological conceptual framework derived chiefly from professional engineers, to describe the nature of technological knowledge in an attempt to contribute towards the understanding of this relatively new learning area.

\section{RESEARCH QUESTIONS}

The following research question is therefore to be addressed:

How useful to technology education is the conceptual framework of knowledge derived chiefly from and used by professional engineers?

If the conceptual framework is found to be useful, it can be used to enhance the understanding of technological knowledge in technology education. The conceptual framework can also be used to evaluate technology learning programmes to determine the extent to which all the knowledge types in technology are represented in those learning programmes.

One way of establishing the usefulness of the conceptual framework, is to determine the frequency with which students engage in the categories of technological knowledge that make up the conceptual framework, during technological designing and making tasks, i.e. capability tasks. Furthermore, by determining the relationship between the extent to which students make use of the categories of technological knowledge in two content areas, one could gain 
insight into the way various knowledge types are used in two different content areas. This can, for example, show if the knowledge contained in one content area significantly favours the categories of knowledge when compared to the knowledge in the other content area.

Following the main research question, the sub-questions are:

- what is the frequency of categories of technological knowledge used by education students when they design and make an artefact?

- what is the relationship, if any, between the categories of technological knowledge used in two different content areas in technology education?

\section{FRAMEWORKS OF KNOWLEDGE IN TECHNOLOGY}

Various authors in the field have presented technological knowledge frameworks. For the purpose of this study, four frequently cited frameworks for technological knowledge will be highlighted to form an idea of the content of technological knowledge. The authors of these frameworks hold different views of technological knowledge deriving from different disciplines in the field. Vincenti (1990:208), in an analysis of historical case studies in aeronautical engineering, identified six categories of technological knowledge: fundamental design concepts, criteria and specifications, theoretical tools, quantitative data, practical considerations, and design instrumentalities.

In a philosophical effort to classify technological knowledge, Ropohl (1997:68-71) recognises five categories of technological knowledge applicable to engineering. They are technological laws, functional rules, structural rules, technical know-how and socio-technological understanding.

De Vries' (2003:13-14) classification of technological knowledge is based on the "main steps" in the development of the LOCal Oxidation of Silicon (LOCOS) technology, i.e. functional nature knowledge, physical nature knowledge, means-ends knowledge and action knowledge.

Bayazit (1993:123) classifies designers' knowledge into two main groups: procedural and declarative knowledge, and identifies another two forms of knowledge, namely design normative knowledge and collaborative design knowledge (Bayazit, 1993:126-127).

Although it seems that these authors have different approaches to classifying technological knowledge into categories, there are relationships between the categories (see Broens \& De Vries, 2003:461; De Vries, 2003:16). The categories of technological knowledge presented by the various authors will be used to derive the conceptual framework of this study and will be discussed later.

\section{CONCEPTUAL FRAMEWORK}

The conceptual framework of this study was derived from three different authors' classifications of technological knowledge discussed earlier. In keeping with Broens and De Vries' (2003:463-464) framework, Vincenti's (1990:208) categories of technological knowledge will be used as basis and will be extended by adding Ropohl's (1997:70) category 
of socio-technological understanding and Bayazit's collaborative design knowledge (1993:123), which both seem to be missing from Vincenti's (1990:208) framework. Table 1 shows the adapted conceptual framework.

Table 1 Conceptual framework adapted from Broens and De Vries (2003:464)

\begin{tabular}{ll}
\hline Category of knowledge & Brief description of the category \\
\hline Fundamental design concepts & $\begin{array}{l}\text { Concepts include the "operating principle" and "normal } \\
\text { configuration" of the device (Vincenti, 1990:208-211). }\end{array}$ \\
\hline Criteria and specifications & $\begin{array}{l}\text { The qualitative goals for the device must be translated to } \\
\text { quantitative goals in concrete technical terms. This } \\
\text { requires knowledge of technical criteria regarding the } \\
\text { device and its use, and the ability to assign numerical } \\
\text { values or limits to the criteria (Vincenti, 1990:211-213). }\end{array}$ \\
\hline Theoretical tools & $\begin{array}{l}\text { Tools include intellectual concepts for thinking about } \\
\text { design, and mathematical methods and theories for } \\
\text { design calculations (Vincenti, 1990:213-216). }\end{array}$ \\
\hline Quantitative data & $\begin{array}{l}\text { Two types of knowledge are distinguished: descriptive } \\
\text { (how things are) and prescriptive (how things should be) } \\
\text { (Vincenti, 1990:216-217). }\end{array}$ \\
\hline Practical considerations & $\begin{array}{l}\text { Derived from experience in practice and include not only } \\
\text { design but production and operation as well (Vincenti, } \\
\text { 1990:217-219). }\end{array}$ \\
\hline Design instrumentalities & $\begin{array}{l}\text { Instrumentalities include procedures, ways of thinking } \\
\text { and judgmental skills applied (Vincenti, 1990:219-220). }\end{array}$ \\
\hline $\begin{array}{l}\text { Socio-technological } \\
\text { understanding }\end{array}$ & $\begin{array}{l}\text { Technical objects have to be optimized while considering } \\
\text { the ecological and psychosocial context of the artefact } \\
\text { (Ropohl, 1997:70). }\end{array}$ \\
\hline $\begin{array}{l}\text { Collaborative design } \\
\text { knowledge }\end{array}$ & $\begin{array}{l}\text { The knowledge development of individuals working in } \\
\text { groups (Bayazit, 1993:126-127). }\end{array}$ \\
\hline
\end{tabular}

The framework shown in table 1 is complex and it should be noted that Vincenti (1990) did not intend his framework to be used for the purpose of this study. The motivation for using the conceptual framework as well as some limitations of using it therefore needs to be addressed.

Motivation for using the conceptual framework

The motivation for choosing Vincenti's (1990) framework is:

- it seems to be the most complete one (Broens \& De Vries, 2003:461);

- Vincenti $(1990: 7,207)$ focuses on knowledge for normal, everyday design; and

- the students who participated in this study had to follow the design process prescribed by the Department of Education (DoE, 2002), and all Vincenti's (1990) categories of knowledge refer to knowledge as related phases in the design process (Broens \& De Vries, 2003: 469). It therefore seemed appropriate to use Vincenti's (1990) framework as the conceptual framework for this study.

Limitations of the conceptual framework

Vincenti (1990:208, 235) admits that neither the categories nor the activities are mutually exclusive and an item of knowledge can belong to more than one category. It is also possible 
that more than one activity, e.g. research and invention, can take place to generate an item of knowledge. In addition, Vincenti (1990:208) acknowledges that the categories of knowledge are not entirely exhaustive: "although the major categories are presumably complete, the subspecies within them most likely are not".

As a result, Broens and De Vries (2003:465) point out that Vincenti's (1990) framework does not follow the two basic rules of classification, viz. that classification should be mutually exclusive and complete. Both rules are, according to them (Broens \& De Vries, 2003:465) more or less broken, but they regard the 'mutually exclusive' rule as the weakest link in Vincenti's (1990) classification scheme.

\section{CONTEXT OF THE STUDY}

\section{Target population}

The target comprised third year undergraduate students at the University of Pretoria, who selected technology as an elective subject as part of their four year Bachelor of Education (BEd) degree course. Novice teacher education students were selected specifically, despite evidence in the literature that indicates that there are several advantages to using "experts" in the field as opposed to novices (see Glaser (1999:91-92).

The question of who the "experts" are in technology education is, however, problematic since technology is a relatively new learning and as a result of the newness of this learning area, the vast majority of practising technology teachers in South Africa do not have formal training in technology education, but were generally sourced from subjects such as home economics, woodwork, metalwork and industrial arts (Van Niekerk, Ankiewicz, \& De Swart, forthcoming). Current technology teachers therefore do not have the relevant academic background in terms of the technology content areas, design process and the methodological approach to technology education. In addition, most of these teachers were not trained in outcomes-based education (OBE) (Potgieter, 2004:210), which underpins the South African education system (DoE, 2002). Technology students at the University of Pretoria, on the other hand, are trained in technology education according to the most recent policy requirements and it is assumed that they are able to design and implement learning programmes successfully.

\section{Sampling}

The sample was a non-random, or non-probability convenient sample (Cohen, Manion, \& Morrison, 2001:92-103; Creswell, 2005:146-149; Neuendorf, 2002:87-88). The sample consisted of two groups of students (most of whom were present in both modules): the first group of 22 students was part of the JOT 353 (systems and control) module and the second group of 21 students was part of the JOT 354 (structures) module. Students who were repeating either or both of the modules accounted for the slight difference in student numbers between the two modules. Both groups were heterogeneous in terms of language, gender and culture, and ranged in age from 20-23 years.

\section{Background}

The operational approach to teaching technology in South Africa is project-based with an emphasis on learner-centredness. Projects consist of coherent units of work spread over an extended period of time, i.e. capability tasks. Capability tasks involve designing and making a product that works (Barlex, 2000). Such capability tasks are conducted over a longer period of 
time using the design process, i.e. investigating, designing, making, evaluating and communicating, as prescribed by the Department of Education (2003:6). Within these longer project time frames, opportunities should be created for shorter and more structured tasks, such as case studies and resource tasks (also known as focused tasks) (DoE, 2003:26).

As part of the students' training, they have to conduct one capability task per content area. These capability tasks are performed during non-contact time (after hours, in their own time) in a constructivist manner. It is assumed that all the third year design and technology students, although they had no previous engagement with the content of systems and control and structures, were competent in following the design process independently, as it had been part of their formal first and second year training.

Since all students' identified needs and artefacts, and therefore the solutions to the problems, are unique, each student would require different knowledge in different phases of the design process. This can, due to a time constraint, be realised only if the students work on their capability tasks in a constructivist manner during non-contact time. Contact time, i.e. classtime, is used only for lecturing, resource and research tasks and case studies.

This study focused on two capability tasks from two different content areas taken by the third year design and technology education students. The students were free to either work independently or to work in pairs for both the capability tasks. The modules involved are JOT 353 and JOT 354.

\section{Module JOT 353}

JOT 353 is a seven-week (50 minutes $\mathrm{x} 4$ periods per week) module in the third term that deals with the content area of systems and control in learning outcome 2 . In this module students had to design and make an educational toy. The toy was required to comprise at least two different mechanical components (e.g. gears, pulleys, levers, etc.), and an electrical circuit. At the end of the module, students had to present the educational toy, as well as a comprehensive project portfolio, documenting the design process followed to design and make the educational toy, for assessment. Figures 1 and 2 are examples of students' educational toys.

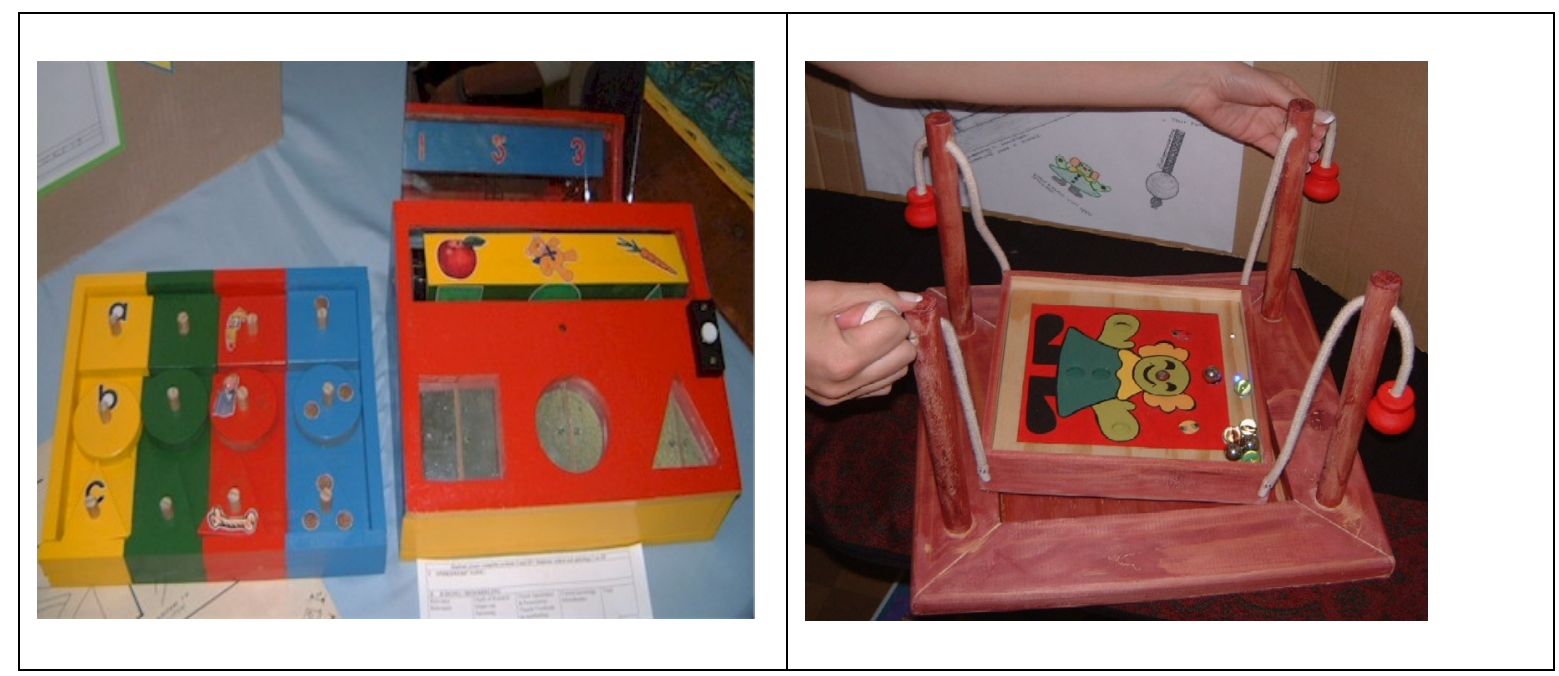

Fig. 1 Educational toy 1

Fig. 2 Educational toy 2 
Figure 1 shows a toy that requires the player to match shapes and colours. A motor turns a spindle if the button is pressed. If the button is released the spindle will stop on one of four colours. The player then needs to insert the correct colour and block shape into the corresponding space on the toy. A light emitting diode (LED) will switch on, indicating that all three shapes have been correctly placed. The educational purpose of this toy is that it will allow the learners to practice colour and shape recognition.

In the toy depicted in figure 2, the player uses four cords and "pulleys" to manipulate a freehanging platform (inclined plane) in order to manoeuvre three metal balls into three holes. An LED will indicate when the player has successfully manipulated the balls into the holes. The educational value of this game is that it improves hand /eye coordination.

\section{Module JOT 354}

JOT 354 was another seven-week (50 minutes $x 4$ periods per week) module offered during the fourth term. This module dealt with the content area of structures in learning outcome 2 and here the capability task required the students to design and make a structural artefact based on and selected from their individual learning programmes drawn up in JMC 300, methodology of technology. As part of their JMC 300 module, all students had to create a complete learning programme for a phase of their choice: The South African Revised National Curriculum Statement (RNCS) is divided into three phases from grades R - 9: the foundation phase (grades $\mathrm{R}-3$ ), the intermediate phase (grades $4-6$ ) and the senior phase (grades $7-9$ ).

These learning programmes had to include all three content areas in each grade, viz. systems and control, structures, and processing. Since technology's teaching strategy is project based, students had to specify a contextualised project as a capability task for each content area for each grade. Students acted as curriculum developers since they were not required merely to select a capability task from a pre-existing set.

In the module JOT 354, students were free to choose any capability task from any grade specified in their learning programme, as conceptualised in JMC 300, which related to the content area of structures. They then had to design and make the artefact as a capability task. They were therefore both the "teacher" as well as the "student" during this last module of their design and technology training.

The reason why students were expected to select capability tasks from their individual learning programmes in JMC 300 was to ensure that they would not have similar capability tasks, since they had all received the same capability task for JOT 353. The intention here was to compare their engagement with the categories of technological knowledge in JOT 353 and JOT 354, to determine whether students engaged differently with the categories of technological knowledge in the two modules.

At the end of the module both the structure artefact as well the project portfolio were assessed for a mark. Figures 3 and 4 are examples of the students' structure artefacts. 


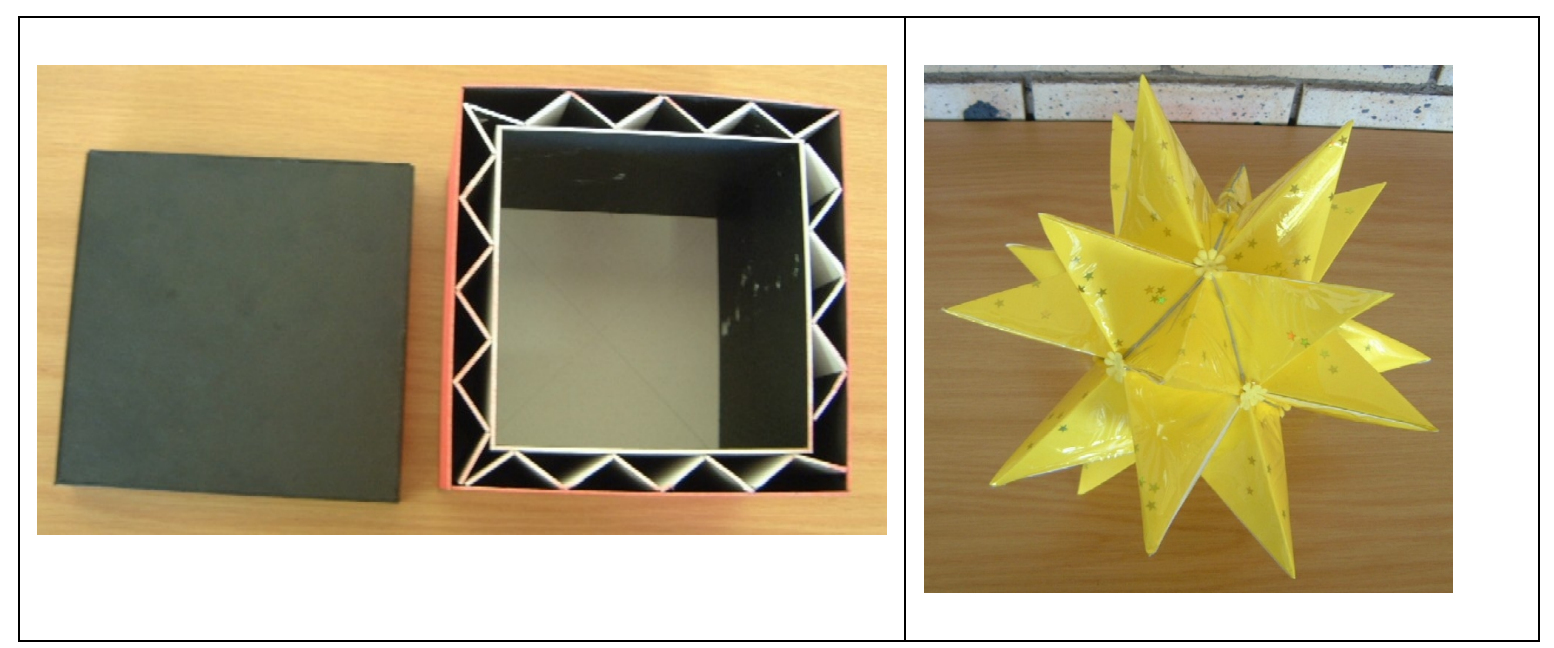

Fig. 3 Structure 1

Fig. 4 Structure 2

Figure 3 is a photograph of a compact disc container (CD box), which was conceptualised to address the assessment standards of structures for grade 6 . The CD box was made from cold pressed paper (a form of cardboard) and strengthened by means of triangular corrugations. It was designed to store 12 compact discs in the context of storage (containerisation).

Figure 4 depicts a Christmas package, which was conceptualised to address the assessment standards of structures for grade 4 . This structure was made by means of folding, tubing, and strong joints in the context of packaging (containerisation), since the purpose of this Christmas package was to contain something such as sweets or a small toy. It is possible to insert something (and take it out again), by means of a triangle that is able to "swing" open.

\section{STRATEGY OF INQUIRY}

Quantitative research was used to provide insight into the categories of knowledge used by students at the University of Pretoria. This study employed a correlation design to determine the relationship between the categories of technological knowledge used in two different content areas in technology education. The rationale for using this design was to relate the extent to which students engaged in the categories of technological knowledge in two different content areas to determine whether the knowledge contained in one content area favour the categories of knowledge above the knowledge contained in the other content area. This correlation could, in addition, help predict whether the categories of knowledge also apply to structures which were not included in this study due to time constraints.

\section{DATA COLLECTION INSTRUMENT}

A questionnaire was used to collect data and the questions were derived from the categories of knowledge listed in the conceptual framework. Rating scale questions were used and students had to indicate the extent to which they made use of the various categories of knowledge by selecting from the following options: "Not at all"; "To a limited extent"; "To a fairly large extent"; and "Extensively".

The questionnaire was piloted at the end of the second term. The module (JOT 310) focused on electrical systems and was the first part of the systems and control module (JOT 353). It was found that the questionnaire was too complex, since some of the students did not 
understand the questions/terminology. The questionnaire was then simplified by stating the questions more simply and by providing short descriptions from Vincenti's (1990) book to explain the concepts. The revised questionnaire was then re-tested on five students who were initially involved in the pilot in an informal interview-like situation. These students found the revised questionnaire easier to complete. By asking probing questions not included in the questionnaire, I tested their understanding of the questions and concepts. From their answers it seemed that they understood the questions and terminology.

Content validity was achieved by deriving the questions for the questionnaire directly from all the categories of knowledge listed in the conceptual framework. A technology education specialist, i.e. the other lecturer who was co-responsible for the development of the design and technology education curriculum at the University of Pretoria, verified that the questionnaire items were representative of all the categories of knowledge.

Vincenti $(1990: 7,207)$ derived his framework from knowledge for normal, everyday design and it can be related to phases in the design process prescribed by the Department of Education (2002). Since the questionnaire was derived from Vincenti's (1990) framework, the data it generates can be generalized (external validity) to other teacher education institutions, as well as to schools, which also follow the design process prescribed by the Department of Education (2002).

\section{RESEARCH LIMITATIONS}

The limitations acknowledged by this researcher include:

- the contextual scope of this study: this study was conducted using one group of undergraduate students from one university only, who selected technology education as an elective subject;

- the focus of this study is limited to technological knowledge in a South African education context - other views on knowledge are not addressed;

- only a limited number of students participated in the research. This is a limitation since it restricts the possibility to make quantitative generalisations; and

- it is accepted that the activities that were performed during contact time had an influence on the way students engaged in technological knowledge when they conducted the capability tasks. It is, however, a limitation of this study that it was not possible to determine the extent of this influence, since the students did not explicitly indicate what knowledge was acquired by themselves or by means of the classroom activities.

\section{RESULTS}

The questionnaire was administered at the end of each module, thus also at the end of the section of work on each content area. For the first content area, systems and control, the students had to design and make an educational toy. For the second content area (structures), the students had to design and make a structural artefact as described in the previous chapter.

The results of the students' responses to the rating scale questions, indicating the extent to which each category of technological knowledge were used to design and make an educational toy (JOT 353) are shown graph 1. 
Graph 1 Number of student responses to the categories of technological knowledge applicable to the educational toy

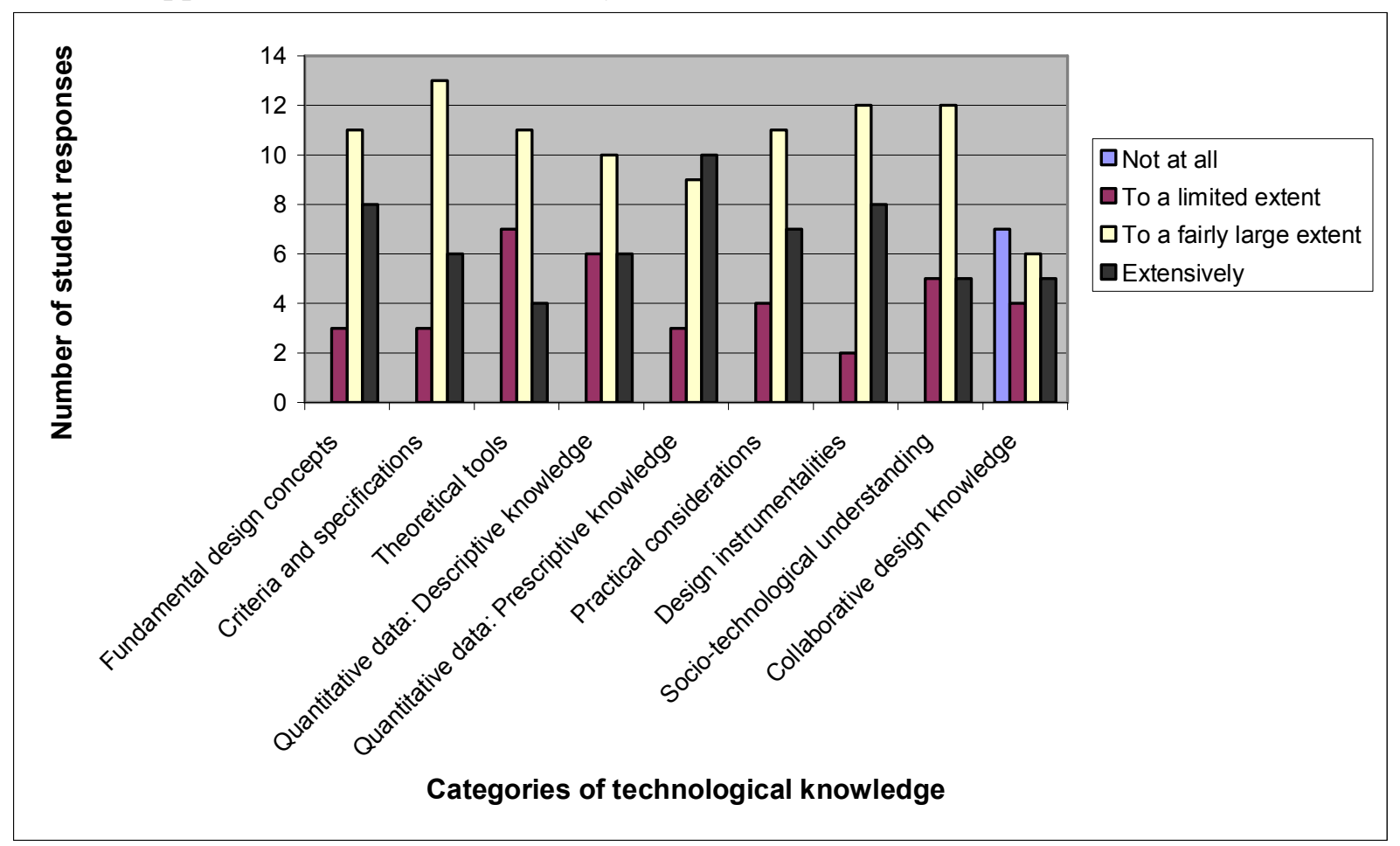

$\mathrm{N}=22$

Graph 1 shows that the JOT 353 students indicated that they engaged predominantly "to a fairly large extent" in seven of the nine (78\%) of the categories of technological knowledge while designing and making the educational toy. This high level of engagement indicated by the students suggests that the categories of technological knowledge, identified chiefly by Vincenti (1990:208), were relevant to this capability task.

In the category of quantitative data, pertaining to prescriptive knowledge, the "extensively" scale was selected by 10 of the 22 students $(45 \%)$, while the "not at all" scale was selected by 7 of the 22 students (32\%) for the category of collaborative design knowledge. It is believed that the students' very low level of engagement in the category of collaborative design knowledge might, at least partly, be attributed to their limited experience and knowledge in general and in regard to technological design specifically. Another possible reason is that because the capability tasks were performed during non-contact time (after hours), students did not always have direct contact with each other, since not all of them lived in campus residences.

The results of the students' responses to the rating scale questions indicating the extent to which each category of technological knowledge was used to design and make a structure artefact (JOT 354), are represented in graph 2. 
Graph 2 Number of student responses to the categories of technological knowledge applicable to the structure artefact

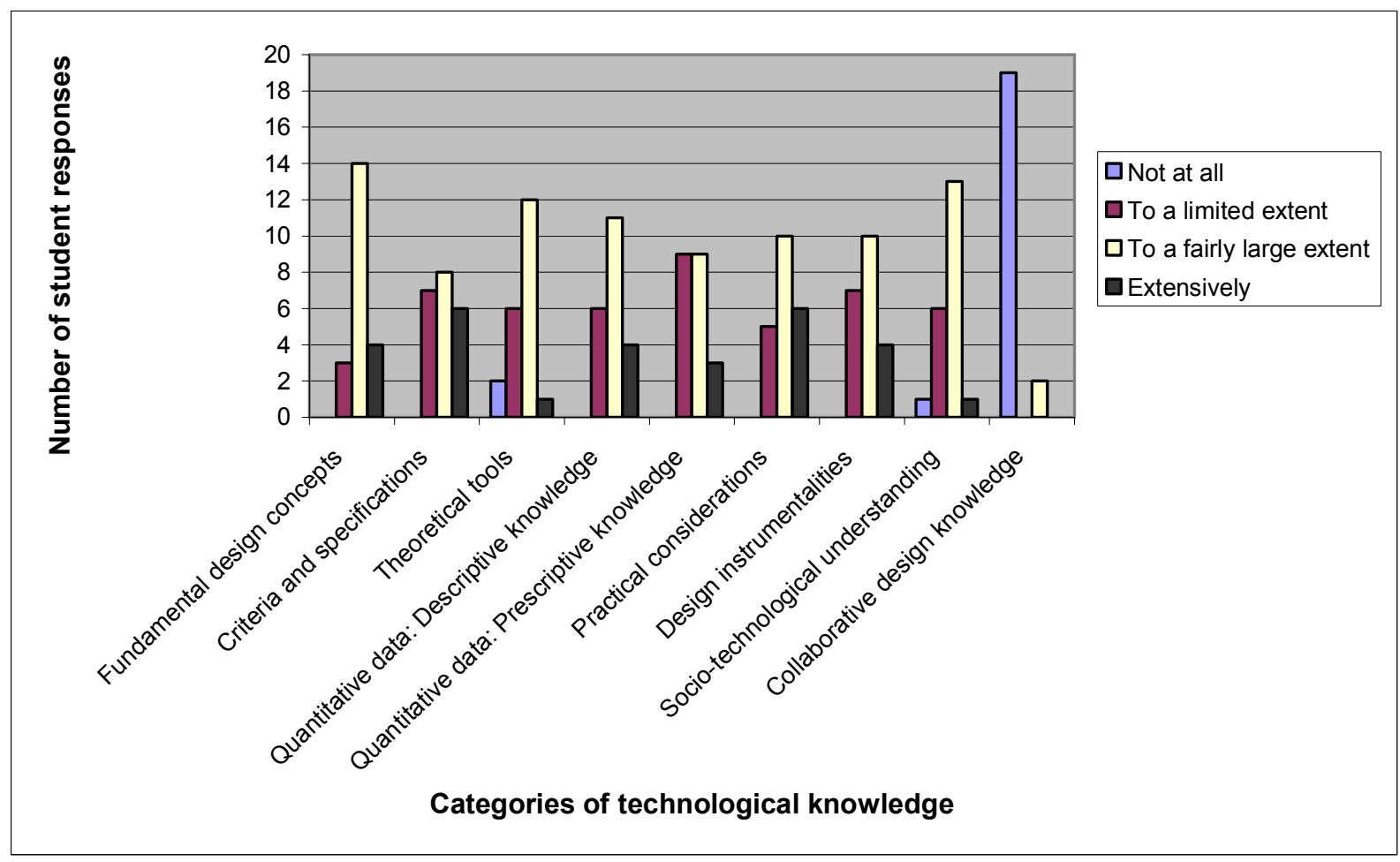

$\mathrm{N}=21$

Graph 2 shows that the JOT 354 students indicated that they again engaged predominantly "to a fairly large extent" in seven of the nine (78\%) categories of technological knowledge during the designing and making of the structural artefact. This high level of engagement indicated by the students, suggests that Vincenti's (1990:208) categories of technological knowledge were also relevant to this capability task.

As with the educational toy, the "not at all" scale was selected by most students (19 out of 21) for the category of collaborative design knowledge. It is suspected that the increase in the number of students who selected this scale (compared to the educational toy scale) could be attributed to the fact that students started to work more in isolation from their team members due to the general increase in workload that they experienced closer to the end of the year. Projects, tasks and tests in their other subjects demanded more of their time.

The category of quantitative data, pertaining to prescriptive knowledge, received an equal number of student responses for the "to a limited extent" and the "to a fairly large extent" scales. This contrasts to an extent with what was found in regard to the educational toy for which this category was used extensively. It seemed that the students steered clear of prescriptive quantitative data in the structure capability task, possibly due to the nature of the structure capability task, which this time did not involve components required to operate within certain parameters.

From the foregoing it seems that the categories of technological knowledge derived from professional engineering are useful to technology education, as evident in the high extent of student engagement in most of the categories of technological knowledge in both content areas. 
Relationship between the extent to which students made use of the categories of technological knowledge in the two content areas

The Pearson product moment correlation coefficient $(r)$ was used to establish whether a relationship exists in the extent to which students made use of the categories of technological knowledge between the two content areas. Table 2 shows the Pearson $r$ for each category of technological knowledge.

Table 2 The relationship between the two content areas of student engagement in the categories of technological knowledge

\begin{tabular}{lc}
\hline Category of technological knowledge & $\boldsymbol{r}$ \\
\hline Fundamental design concepts & +.88 \\
\hline Criteria and specifications & +.76 \\
\hline Theoretical tools & +.90 \\
\hline Quantitative data: Descriptive knowledge (how things are) & +.96 \\
\hline Quantitative data: Prescriptive knowledge (how things should be) & +.35 \\
\hline Practical considerations & +.98 \\
\hline Design instrumentalities & +.72 \\
\hline Socio-technological understanding & +.90 \\
\hline Collaborative design knowledge & +.83 \\
\hline
\end{tabular}

For a study involving 22 students, $\left(\mathrm{df}^{2}=20\right)$, a coefficient of .54 is needed to be significant ${ }^{3}$ at the .01 level (Ary et al., 2002:361,548). Eight of the nine relationships shown in table 2 were statistically significant at the .01 level, since their $r$ values are higher then .54 . Since there is only a 1 in 100 possibility of chance, these relationships are unlikely to be a function of chance.

One relationship, for the category of quantitative data pertaining to prescriptive knowledge, however, is significant only at the .10 level, with an $r$ value of .35. This lower level of significance means that the relationship has a higher probability of being a function of chance (1 in 10) than the other eight relationships shown in table 2.

Jackson's (2006:124) estimates were used to interpret the Pearson product-moment correlation coefficient in table 2. According to these estimates do eight of the nine categories of knowledge listed in table 2 show a strong positive relationship between the two content areas. Only the category of quantitative data that relates to prescriptive knowledge shows a moderate positive relationship between the two content areas. This suggests that the students engaged in the knowledge from the categories of technological knowledge to nearly the same extent in both content areas, which implies that the knowledge contained in one content area, i.e. systems and control, does not significantly favour the categories of knowledge above the knowledge contained in the other content area, i.e. structures. It also seems to indicate that there is no difference in the way in which students engage in the categories of technological knowledge in different capability tasks in JOT 354 compared to JOT 353 where all the students had the same capability task.

A possible reason for this is that Vincenti $(1990: 7,207)$ derived the categories from historical cases which focused on knowledge for normal, everyday design. In addition, all his categories

\footnotetext{
${ }^{2} \mathrm{df}=\mathrm{N}-1$

${ }^{3}$ Significant means "less likely to be a function of chance than some predetermined probability" (Ary, et al., 2002:179).
} 
refer to knowledge related to steps or phases in the design process (Broens \& De Vries, 2003:469). Since the students had to follow the prescribed design process to design and make their artefacts, they were bound to engage in these categories of knowledge in more or less the same way, as they are directly and indirectly embedded in the assessment standards of the RNCS for technology (DoE, 2002). The implication is that the categories of technological knowledge used in the conceptual framework of this study apply to all three content areas.

\section{CONCLUSION}

The results from this study seem to indicate that the epistemological conceptual framework chiefly derived from and used by professional engineers, is useful to technology education. This is evident in the high level of student engagement in most of the categories of technological knowledge in both content areas. In addition, the findings suggest that the categories of technological knowledge apply to all three technology content areas (i.e. systems and control, structures and processing). It must, however, be reiterated that the sample size was limited which restricts broader generalisations.

By considering the categories of technological knowledge presented in the conceptual framework of this study, educators can deepen their understanding of the nature of technological knowledge as recommended by the Department of Education (2003:31). In this regard Herschbach (1995:31) contends that "a deeper understanding of technological knowledge opens the curriculum to possibilities that are obscured by a more restricted view. Greater direction is also given to the task of curriculum development".

One important aspect in the 'usefulness' of the framework is that it can be used to evaluate technology learning programmes to determine the extent to which all the knowledge types in technology are represented in those learning programmes. Another 'use' of the framework is that it is apparently able to distinguish between two capability tasks, showing how they differ in what knowledge is used. This is significant if one wants to use the framework to determine whether one course is better in regard to displaying the full spectrum of technological knowledge than another.

In order to "operationalise" the conceptual framework used in this study, educators must consciously attempt to include items of knowledge from each category of knowledge when conceptualising capability tasks for their learning programmes. The inclusion of knowledge from each category of knowledge will ensure an integration of the three learning outcomes, since they are all addressed in the conceptual framework and will therefore help to overcome/prevent a fragmented approach to teaching technology education.

\section{REFERENCES}

Ankiewicz, P., De Swart, E., \& De Vries, M. J. (2006). Some implications of the philosophy of technology for science, technology and society (STS) studies. International Journal of Technology and Design Education, 16(2), 117-141.

Ary, D., Jacobs, L. C., \& Razavieh, A. (2002). Introduction to research in education. Belmont: Wadsworth/Thomson learning.

Barlex, D. (1998). Design and technology - the Nuffield perspective in England and Wales. International Journal of Technology and Design Education, 8(2), 139-150. 
Barlex, D. (2000). Perspectives on departmental organisation and children's learning through the Nuffield design and technology project. In J. Eggleston (Ed.), Teaching and learning design and technology (pp. 91-103). London: Continuum.

Bayazit, N. (1993). Designing: Design knowledge: Design research: Related sciences. In M. J. De Vries, N. Cross \& D. P. Grant (Eds.), Design methodology and relationships with science (pp. 121-136). Dordrecht: Kluwer.

Broens, R. C. J., \& De Vries, M. J. (2003). Classifying technological knowledge for presentation to mechanical engineering designers. Design Studies, 24(5), 457-471.

Cohen, L., Manion, L., \& Morrison, K. (2001). Research methods in education. London: Routledge Falmer.

Compton, V. (2004). Technological knowledge: A developing framework for technology education in New Zealand (Briefing paper prepared for the New Zealand Ministry of Education Curriculum Project).

Creswell, J. W. (2005). Educational research: Planning, conducting and evaluating quantitative and qualitative research. New Jersey: Pearson Prentice Hall.

De Vries, M. J. (2003). The nature of technological knowledge: Extending empirically informed studies into what engineers know. Techné: Research in Philosophy and Technology, 6(3), 1-21.

De Vries, M. J. (2005). Teaching about technology: An introduction to the philosophy of technology for non-philosophers. Dordrecht: Springer.

De Vries, M. J., \& Tamir, A. (1997). Shaping concepts of technology: What concepts and how to shape them. International Journal of Technology and Design Education, 7(12), 3-10.

Department of Education. (2002). Revised National Curriculum Statement for Grades R-9 (Schools) for Technology. Pretoria: Department of Education.

Department of Education. (2003). Revised National Curriculum Statement Grades R-9 (Schools): Teacher's guide for the development of learning programmes - Technology.

Gerring, J. (2004). What is a case study and what is it good for? American Political Science Review, 98(2), 341-354.

Gibson, K. (2008). Technology and technological knowledge: A challenge for school curricula. Teachers and Teaching: Theory and practice, 14(1), 3-15.

Glaser, R. (1999). Expert knowledge and processes of thinking. In R. McCormick \& C. Paechter (Eds.), Learning \& Knowledge (pp. 88-102). London: Paul Chapman

Herschbach, D. R. (1995). Technology as knowledge: Implications for instruction. Journal of Technology Education, 7(1), 31-42.

Jackson, S. L. (2006). Research methods and statistics: A critical thinking approach. Singapore: Thomson Wadsworth.

Jones, A. (2003). The development of a National Curriculum in technology for New Zealand. International Journal of Technology and Design Education, 13(1), 83-99.

Mawson, B. (2007). Factors affecting learning in technology in the early years at school. International Journal of Technology and Design Education, 17(3), 253-269.

Mitcham, C. (1994). Thinking through technology. Chicago: The University of Chicago Press.

Neuendorf, K. A. (2002). The content analysis guidebook. London: Sage publications.

Neuman, W. L. (2006). Social research methods: Qualitative and quantitative approaches. Boston: Pearson.

Pavlova, M. (2005). Knowledge and values in technology education. International Journal of Technology and Design Education, 15(2), 127-147.

Potgieter, C. (2004). The impact of the implementation of technology education on in-service teacher education in South Africa (impact of technology education in the RSA). International Journal of Technology and Design Education, 14(3), 205-218. 
Ropohl, G. (1997). Knowledge types in technology. International Journal of Technology and Design Education, 7(1-2), 65-72.

Rowell, P. M., Gustafson, B. J., \& Guilbert, S. M. (1999). Characterization of technology within an elementary science program. International Journal of Technology and Design Education, 9(1), 37-55.

Van Niekerk, E., Ankiewicz, P., \& De Swart, E. (forthcoming). A process-based assessment framework for technology education: A case study. International Journal of Technology and Design Education Retrieved 12 March, 2008, from http://www.springerlink.com/content/bu7x138637x15282/fulltext.pdf

Vincenti, W. G. (1990). What engineers know and how they know it. Baltimore/London: Johns Hopkins University Press. 